\title{
Physicochemical and Nutritional Characterization of Mushroom Powder Enriched Muffins
}

\author{
Muhammad Farooq ${ }^{1 *}$,Allah Rakha ${ }^{2}$,Jawad U1Hassan ${ }^{2}$, Iftikhar Ahmed Solangi ${ }^{1}$,A.Shakoor ${ }^{3}$, Muhammad \\ Bakhtiar $^{4}$, Muhammad Noman Khan ${ }^{5}$, Shoaib Khan ${ }^{5}$, Ibrar Ahmad ${ }^{6}$, Shabir Ahmed ${ }^{7}$ and Wang Yunyang ${ }^{*}$
}

${ }^{1}$ College of Food Science and Engineering, Northwest $A$ \& $F$ University, Yangling 712100, Shaanxi, China; ${ }^{2}$ National Institute of Food Science and Technology, University of Agriculture Faisalabad, Pakistan; ${ }^{3}$ Beijing Key Laboratory of Quality Evaluation Technology for Hygiene and Safety of Plastic, Beijing Technology and Business University, Beijing, 100048, China; ${ }^{8}$ Department of Agronomy, University of Agriculture Peshawar, Khyber Pakhtunkbwa, Pakistan; ${ }^{5}$ Department of Horticulture, The University of Agriculture Peshawar, Khyber Pakhtunkbwa, Pakistan; ${ }^{6}$ Soil and Environmental Sciences, The University of Agriculture Peshawar, Khyber Pakhtunkhwa, Pakistan; ${ }^{7}$ Assistant Director Food, Zhob Baluchistan, Pakistan.

\begin{abstract}
At global level many species of eatable mushrooms have been used for diet and medication purposes. In addition to its dietetic value mushroom have many medicinal importance because mushroom is used against several viral, bacterial and cancer diseases. Mushroom powder also used to reduce blood pressure and increase resistance of person against many diseases. Keeping in perspective the position of dietary and medicinal values of mushroom in this research mushroom powder was added into muffins to improve nutritious and dietetic status of muffin. To achieve desired objective mushroom powder was mixed with wheat flour to improve sensory attributes of muffins. The proximate analysis of mushroom based powder and wheat flour was also performed. After this loaf weight and volume, structural examination, sensual attributes of muffin were also performed. The effect of mushroom powder on moisture, crude protein crude fat and nitrogen free extract of muffin were non-significant and effect on ash and crude fiber were significant when $0 \%, 10 \%, 20 \%, 30 \%$ and $40 \%$ mushroom powder based muffin were prepared. The effect of mushroom powder supplementations on loaf weight of muffin was significant and resulted in gradual decrease. However, the effect on loaf volume of muffins was non-significant. The effects of mushroom powder on texture and color value of muffin were highly significant. The results of sensory evaluation showed that muffin prepared with $10 \%$ mushroom powder have high sensory score while muffins prepared with $40 \%$ mushroom powder had very low sensory score.

Received | January 16, 2021; Accepted | February 15, 2021; Published | May 28, 2021

*Correspondence | Yunyang Wang and Muhammad Farooq, College of Food Science and Engineering, Northwest AandF University, Yangling 712100, Shaanxi, China; Email: wyy10421@163.com, farooq.fst28@gmail.com

Citation | Farooq, M., Rakha, A., Hassan,J.U., Solangi, I.A., Shakoor, A., Bakhtiar, M., Khan, M.N., Khan, S., Ahmad, I., Ahmed, S. and Yunyang, W., 2021. Physicochemical and nutritional characterization of mushroom powder enriched muffins. Journal of Innovative Sciences, 7(1): 110-120. DOI | https://dx.doi.org/10.17582/journal.jis/2021/7.1.110.120

Keywords | Muffins, Mushroom flour, Physicochemical, Dietry fibre, Wheat flour
\end{abstract}

\section{Introduction}

A t global level many species of eatable mushrooms have been used for diet and medication purposes. Mushroom is the best from nutrition point of view concerning human health, diet, (Salehi and Kashaninejad 2016; Lebesi and Tzia, 2011) and its can also be used for hindrance of infection Mushroom basically is the variety of molds which frequently produce in cool areas and it frequently spread through spores to the different places. Mushroom is useful for diet manufactured goods which are utilized into raw forms and it also used into different food products through process of cooking. Recently, mushroom is 
consumed due to its typical flavor, better quality and it also help in many disease prevention (Kaul, 2011).

In 2007 mushroom consumption at global level was 3.4 million tonnes per year. This mushroom consumption rise about 56\% since 1997. Many types of mushroom species which are utilized as food belong to family Basidiomycetes and Agaricaceae. Mushroom plant cannot produce own food because it has not chloroplast. Mushroom (Auricularia auricular) is grown in many countries for food as well as medicinal purposes Aida et al. (2009), Islam et al. (2016), Reis et al. (2017). It was first cultivated in China around 6000 A.D. After this, mushroom cultivation started in European countries. There are almost 12000 species of mushroom in which 2000 species are edible and 200 species are used for medical purposes. (Aida et al., 2009; Islam et al., 2016; Reis et al., 2017) Most important cultivated types of mushrooms are Agaricus bisporus (button mushroom), Lentinus edodes (shiitake), Pleurotus spp (oyster mushroom), Auricula auricular (wood mushroom), Flamulina velutipes (winter mushroom) and Volvariella volvacea (straw mushroom) (Aida et al., 2009). Dietary supplements that are obtained from mushroom are fruiting bodies of mushroom and consumed in form of capsules, tablets and extract (Svec and Hruskova, 2004; Salehi et al., 2017).

Mushroom is an excellent source of protein (44\%), crude fiber (7\%) and minerals (4\%). Calcium, manganese, magnesium and iron are important minerals which are found in Mushroom also contains $27 \%$ moisture content and $18 \%$ carbohydrate content. The two most important bioactive components in mushrooms are adenosine and cordycepin. The total amino acid content in mushroom ranges from 35 to $37 \%$. Glutamic acid and aspartic acid are two important amino acid found in mushroom. (Salehi et al., 2016; Khan et al., 2017) mushroom powder is added in muffin to fulfill specific nutrient deficiency. Normally, bakery products like muffin do not contain high protein so mushroom powder is added to increase their protein content. Mushroom powder improves taste and flavor and sensory properties of muffins. Mushroom powder is also excellent source of vitamin $\mathrm{D}$, selenium, chromium. It has effects on physical and chemical properties of muffin loaf. It increases muffin firmness by decreasing size of loaf (Corey et al., 2006). Furthermore, mushroom also provide resistance and immunity against sleeplessness, tumor growth, diabetes, asthma, cholesterol reduction, allergies and anxiety (Ibrahium and Hegazy, 2014; Rathore and Prasad, 2017). Drying is a relatively cost-effective method than other approaches of preservation. The key advantage of drying is that if dried mushrooms are filled in sealed jars, its shelf life will be more than one year. Drying rate is influenced by many factors including thickness of the mushroom, moisture diffusivity, temperature and method of drying. Solar drying may be considered as an expansion of sun drying. It is a competent system of consuming solar energy. Muffins are utilized in routine diet in the whole world and it is one of the most nutritious product in bakery products. Muffin is very less expensive bakery product. It has also many beneficial properties. Muffins are available in market into different forms, have good taste and flavor. For fortification of different nutrients like protein, fat, fiber baker always mixes mushroom powder because mushroom powder is excellent source of valuable nutrients in food products (Ibrahium and Hegazy, 2014). Main ingredients of muffin are white flour, oil, sugar, eggs, baking powder and whole milk. Muffin which is cereal based product is naturally low in protein. Its protein fortification can be used to improve the nutritional health of the people and can be used to reduce protein malnutrition in developing countries (Badifu et al., 2005). Keeping in perspective the position of dietary and medicinal mushroom, this study is designed to enhance dietary and physicochemical properties of mushroom powder enriched muffins and to find out the nutritional profiling of mushroom enriched muffins and assessment of their antioxidant potential.

\section{Materials and Methods}

\subsection{Procurement of raw material}

Oyster mushroom was purchased from mushroom lab of Institute of Horticultural Science, remaining raw material was purchased from local market.

\subsection{Development of mushroom powder}

Drying of mushroom was done with dehydrator at temperature $54^{\circ} \mathrm{C}$ for 25 minutes. After this dried mushroom was converted into powder form with help of grinder.

\subsection{Proximate analysis}

Proximate analysis of white flour and mushroom powder were performed according to their respective 
methods described in AACC (2000).

\subsection{Moisture content}

The moisture content of white flour was measured according to Method no. 44-15 A, as described in AACC (2000). The flour was taken into three separate china dishes, weighed and then placed the sample in hot air oven for 24 hours at $105^{\circ} \mathrm{C}$ for drying. Then sample was again weighed. After this sample was placed again in oven till constant weight. The following formula was used to calculate the percentage of moisture:

Moisture (\%) $=\frac{w t \text {. of original sample }- \text { wt. of dried sample }}{\text { Weight of original sample }} \times 100$

\subsection{Ash content}

The ash content of white flour sample was determined by the method no. 08-01, as described AACC (2000). Quantity of $3 \mathrm{~g}$ of dried white flour sample was taken in a crucible and heated on a flame till it become smokeless. The crucible was placed into muffle furnace at $550^{\circ} \mathrm{C}$ for 4 hours till the sample become greyish white residues. The sample was cooled in a desiccator and weighed. The ash in the sample was calculated according to this formula:

$$
\text { Ash (\%) }=\frac{\text { Weight of residue after incineration }}{\text { Weight of sample }} \times 100
$$

\subsection{Crude fat}

The crude fat was determined according to method no. 30-25 as described in AACC (2000) The soxhlet apparatus was used to determine fat contents. Crude fat from $5 \mathrm{~g}$ of flour was extracted with hexane at a condensation rate of 2-3 drops/sec for 16 hours. After distillation extraction flask with excess hexane residue was dried at $100^{\circ} \mathrm{C}$ for 30 minutes, until a constant weight obtained. Crude fat was calculated by using the following formula as given below:

$$
\text { Fat }(\%)=\frac{\text { Wt. of ether extract }}{\text { Wt. of sample }} \times 100
$$

\subsection{Crude fiber}

The white flour samples were tested after fat extraction for determination of crude fiber content by following the Method no. 32-10, as described in AACC (2000) Quantity of $2 \mathrm{~g}$ fat free white flour sample was taken in a $500 \mathrm{ml}$ capacity beaker and $200 \mathrm{ml}$ of $1.25 \%$ sulphuric acid was added to it and level of beaker was marked. The contents of the beaker were filled for 30 minutes. The contents were filtered and 2-3 washing with hot water were given till it becomes acid free. The residues were transferred to $500 \mathrm{ml}$ beaker again and $200 \mathrm{ml}$ of $1.25 \% \mathrm{NaoH}$ was added to it. The contents were again boiled for 30 minutes. The contents were filtered and 2-3 washing with hot water were given until it became alkali free. The residues were carefully transferred to a china dish and dried in an oven at $100^{\circ} \mathrm{C}$ for $3-4$ hours until constant weight was obtained. The contents were heated on flame until the smoke stopped to come out of the sample. Then the sample was placed in a muffle furnace at $550^{\circ} \mathrm{C}$ for 4 hours until a greyish ash was obtained, then cooled in desiccator and weighed. The difference in weight was calculated as crude fiber using the following formula:

$$
\text { Crude fiber }(\%)=\frac{\text { weight of residue after drying }- \text { weight on ignition }}{\text { Weight of sample }} \times 100
$$

\subsection{Crude protein}

The percentage of nitrogen content in white flour sample was determined by Kjeldhal method as described in AACC (2000) Method no. 46-10. The white flour sample $2 \mathrm{~g}$ was taken in digestion flask and $5 \mathrm{~g}$ digestion mixture and $30 \mathrm{~mL}$ conc. sulphuric acid was added. Then the sample was heated and digested for 2-3 hours till light green color appeared. After this mixture was taken in $250 \mathrm{~mL}$ flask and volume was made by adding distal water $10 \mathrm{~mL}$ from dilution which was taken in Kjeldhal apparatus and $10 \mathrm{~mL}$ of $\mathrm{NaOH}$ was added in it. After this another beaker $10 \mathrm{~mL}$ boric acid was taken and 1-2 drops of methyl red indicator were added. Steam was provided and ammonia gas was trapped in boric acid. This process was continued for 2 minutes when red color of boric acid was changed to golden. The boric acid was titrated with $0.1 \mathrm{~N}$ sulphuric acid solutions till light golden yellow point. The nitrogen percentage was calculated by following formula:

$$
\mathrm{N}(\%)=\frac{\text { Titer of } 0.1 \mathrm{~N} \mathrm{H} 2 \mathrm{SO} 4 \mathrm{used} \times 0.0014 \times 250}{\text { Weight of sample } \times \text { Vol. of aliquot sample }} \times 100
$$

\subsection{Nitrogen free extract (NFE)}

NFE was calculated by subtracting the percentage of moisture, ash, crude protein, fat and crude fiber from as formula by Mahamud et al. (2012).

NFE $(\%)=100-$ (moisture $\%+$ crude protein $\%+$ crude fat $\%+$ crude fiber $\%+$ ash $\%$ 
2.10 Product development

White flour in muffin was replaced by mushroom powder as described in treatments.

\subsection{Muffin preparation}

Muffins were prepared with supplemented blends and with control treatment as mentioned in table by the following method:

\begin{tabular}{ll}
\hline Egg & 10 \\
Sugar & $450 \mathrm{~g}$ \\
Oil & $1 / 2 \mathrm{~L}$ \\
White flour & $1 \mathrm{~kg}$ \\
Bakingpowder & $30 \mathrm{~g}$ \\
Whole milk & $400 \mathrm{ml}$ \\
\hline
\end{tabular}

Sugar and oil were mixed in mixing pan and shake well for 6 minutes. Then egg, flour and baking powder was added and shaken well till grains of sugar became completely dissolved. Liquid milk was added in pan and thoroughly mixed for 2 minutes till viscous batter was obtained. Add any color and flavor in batter. Butter paper was placed in muffin pans and then batter was placed with spoon. Each pan filled with $1 / 2$ to $2 / 3$ of batter. 12 pan were placed in baking tray. Baking tray was placed in the oven at $175^{\circ} \mathrm{C}$ for $15-$ 20 minutes. After this baking tray was removed from oven and muffins were cooled at room temperature (Aguilera et al., 2009).

\subsection{Chemical analysis of muffin}

Muffin was analyzed for the proximate analysis which includes moisture, ash, crude protein, crude fat, crude fiber and NFE according to their respective methods described by AACC (2000) as described earlier.

\subsection{Physical analysis of muffin loaf weight and volume}

Loaf weights and volumes of muffins was measured after 1-hour removal from the oven. Loaf was weighed using an electronic balance and loaf volume was measured by rapeseed displacement method given in AACC (2000). Each loaf was put in a container and covered with rapeseeds totally filled the container. Then the loaf was removed and the volume of rapeseed was recorded by the method of Keskin et al. (2004). Specific volume was measured by dividing loaf weight to loaf volume.

\subsection{Texture analysis}

The textural study of muffin was conducted by using Texture analyzer with a $5 \mathrm{~kg}$ load cell as described by
Piga et al. (2005) It is an automatic equipment having software attached which gives the measurements of the hardness and resistance of the muffin to bend or snap. The Texture Expert program version 4 was used for data analysis. Texture analyzer has three- point bending rig (HDP/ 3BP) using $5 \mathrm{~kg}$ load cell heavy duty platform (HDP/ 90). Three muffins of each treatment were analyzed for the hardness (firmness) and factorability.

\subsection{Scanning analysis of muffins}

Scanning electron microscopy analysis of muffin samples was done by SEM (Hitachi 2380N, Ibaraki, Japan) equipped with field emission gun, a back secondary electron detector from central $\mathrm{Hi}-\mathrm{Tech}$ Laboratory of University of Agriculture, according to method of Kim et al. (2001) to determine the pore size description and micro-structural features related texture of muffin.

\subsection{Color of muffin}

The muffin crust and crumb color was determined by colorimeter according to method described by Rocha and Morais (2003) with some modifications. It was first calibrated with the standards $\left(54^{\circ} \mathrm{C} \mathrm{Tn}\right.$ for dark and $151^{\circ} \mathrm{C}$ Tn for light). After this muffin sample were filled in petri plates, to get the optimum reflection of light, emerged by the photo cells of the color meter, reading was noted from display.

\subsection{Sensory evaluation of muffin}

The prepared muffin loaves were evaluated by a panel of judges for external characteristics such as volume, crust color, symmetry of form, evenness of bake and internal characteristics like grain, crumb color, aroma, taste and texture by following the method of Land and Shepherd (1988).

\subsection{Statistical analysis}

Standard statistical procedure was applied according to method described by Steel et al. (1997).

\section{Results and Discussion}

Mushroom was dehydrated with help of dehydrator. After dehydration mushroom was changed in mushroom powder. The proximate analysis of mushroom powder and wheat flour was also performed. After this loaf weight, volume, structural examination and sensory attributes of muffin were also performed. 
Table 1: Experimental plan $T_{0}$ will be considered as control with no mushroom powder.

\begin{tabular}{lll}
\hline Treatment & Mushroom powder (\%) & White flour (\%) \\
\hline $\mathrm{T}_{\mathrm{o}}$ & 0 & 100 \\
$\mathrm{~T}_{1}$ & 10 & 90 \\
$\mathrm{~T}_{2}$ & 20 & 80 \\
$\mathrm{~T}_{3}$ & 30 & 70 \\
$\mathrm{~T}_{4}$ & 40 & 60 \\
\hline
\end{tabular}

\subsection{Proximate analysis of white flour and mushroom powder}

Proximate composition of white flour and mushroom powder are shown in the Table 2. Wheat flour contained $12.50 \pm 0.43 \%$ moisture, $0.35 \pm 0.01 \%$ ash, $9.45 \pm 0.03 \%$ crude protein, $0.30 \pm 0.01 \%$ crude fiber, $1.25 \pm 0.04 \%$ crude fat and $76.15 \pm 2.66 \% \mathrm{NFE}$. Likewise, mushroom powder contained $7.36 \pm 0.29 \%$ moisture, $6.09 \pm 0.21 \%$ ash, $28.69 \pm 1.09 \%$ crude protein, $8.16 \pm 0.0 .28 \%$ crude fiber, $1.88 \pm 0.04 \%$ crude fat and $47.82 \pm 1.84 \% \mathrm{NFE}$, respectively. These values lie within the range mentioned by Dikeman et al., (2005). The values of wheat flour and mushroom powder are according to the values mentioned by Bano and Rajarathnian (1998).

Table 2: Proximate values of Mushroom powder and white flour.

\begin{tabular}{lll}
\hline Parameters & Mushroom powder & White flour \\
\cline { 2 - 3 } & Percentage & Percentage \\
\hline Moisture & $7.36 \pm 0.29$ & $12.50 \pm 0.43$ \\
Ash & $6.09 \pm 0.21$ & $0.35 \pm 0.01$ \\
Crude protein & $28.69 \pm 1.09$ & $9.45 \pm 0.03$ \\
Crude fiber & $8.16 \pm 0.28$ & $0.30 \pm 0.01$ \\
Crude fat & $1.88 \pm 0.04$ & $1.25 \pm 0.04$ \\
NFE & $47.82 \pm 1.84$ & $76.15 \pm 2.66$ \\
\hline
\end{tabular}

\subsection{Chemical analysis of muffin moisture content}

The analysis of variance regarding moisture of different supplemented muffin is shown in Table 3 . It is obvious from the Table 3 that moisture content was not significantly affected by supplementation of mushroom powder in muffin at different levels. The mean values of moisture for muffin treatments $\mathrm{T}_{0} \mathrm{~T}_{1}$, $\mathrm{T}_{2} \mathrm{~T}_{3}$ and $\mathrm{T}_{4}$ were $4.46 \%, 12.51 \%, 13.12 \%, 13.14 \%$ and $13.17 \%$, respectively as shown in Table 3 .

\subsection{Ash content}

The analysis of variance regarding ash content of different supplemented muffin is shown in Table 3. The mean values of ash in muffin treatments $\mathrm{T}_{0}, \mathrm{~T}_{1}$,
$\mathrm{T}_{2} \mathrm{~T}_{3}$ and $\mathrm{T}_{4}$ were $0.35 \%, 0.36 \%, 0.38 \%, 0.39 \%$ and $0.41 \%$, respectively as shown in Table 3 . The ash content is generally influenced by environmental conditions and malnutrition stages of wheat grains. It is influenced by the level of supplementation of wheat flour with other Oyetaya et al. (2007).

\subsection{Crude protein}

It is obvious from Table 3 that protein content in all types of muffin supplemented with mushroom powder increased by increasing the level of mushroom powder. The analysis of variance regarding protein content of different supplemented muffin is shown in Table 2 . The mean values of crude protein in muffin treatments $\mathrm{T}_{0}, \mathrm{~T}_{1}, \mathrm{~T}_{2}, \mathrm{~T}_{3}$ and $\mathrm{T}_{4}$ were $9.45 \%, 9.47 \%$, Oyetaya et al.'(2007).

9.51\%, 9.55\% and 9.59\% respectively as shown in Table 3. Hesham et al. (2007) reported that total protein content in biscuits only $0.64 \%$ with each increment of mushroom powder. Hong et al. (2005) conducted study on the effect of mushroom powder on bread baking. In this study they reported that level of protein increased in bread with increase of mushroom powder level that may be due to high level protein content in mushroom powder.

\subsection{Crude fiber}

The analysis of variance regarding crude fiber content of different supplemented muffin is shown in Table 3. The mean values of crude fiber in muffin treatments $\mathrm{T}_{0}, \mathrm{~T}_{1}, \mathrm{~T}_{2}, \mathrm{~T}_{3}$ and $\mathrm{T}_{4}$ were $0.30 \%, 0.31 \%, 0.33 \%$, $0.34 \%$ and $0.35 \%$, respectively as shown in Table 3 . The results showed that crude fiber content varied significantly among different composite flours due to the variation in level of supplementation. In urban areas of Pakistan white flour which is obtained from wheat flour is consumed for muffin preparation. The $\%$ age of fiber content in muffin obtained in this study were close to the values of fiber content in the study conducted by Oyetaya et al. (2007).

\subsection{Crude fat}

The statistical results presented in Table 3 indicated that the fat content in muffin supplemented with mushroom powder not varied significantly due to variation in supplementation levels. The effect of mushroom powder supplementation level on the fat content of different mushroom powder supplemented muffin is given in Table 3. The results of the present study were similar to the results obtained by study of 
Hesham et al., 2007 who reported that fat content were increased by the addition of mushroom powder and legume seeds.

\subsection{Nitrogen free extract}

The statistical analysis for nitrogen free extract (NFE) of the mushroom powder supplemented muffin are shown in Table 4. The mean values of NFE in muffin treatments $\mathrm{T}_{0}, \mathrm{~T}_{1}, \mathrm{~T}_{2}, \mathrm{~T}_{3}$ and $\mathrm{T}_{4}$ were $76.15 \%$, $76.09 \%, 75.38 \%, 75.28 \%$ and $75.17 \%$, respectively as shown in Table 3 The results revealed that there was not significant effect of mushroom powder supplementation on the NFE of muffin.

\subsection{Physical analysis of muffin}

Loaf weight and volume (rapeseed displacement method): The statistical analysis regarding the loaf volume of muffin prepared from the mushroom powder supplemented composite flour is given in Table 4. The mean of muffin loaf volume for treatments $\mathrm{T}_{0}, \mathrm{~T}_{1}, \mathrm{~T}_{2}, \mathrm{~T}_{3}$ and $\mathrm{T}_{4}$ were $250,254,259,252$ and 255 respectively as shown in Table 4 . The results indicated that loaf volume of muffin was affected no significantly by different level of mushroom powder.

Specific loaf volume is measured by dividing volume of muffin loaf to the weight of muffin loaf. The analysis of variance regarding specific volume is shown in Table 4. The mean of loaf weight in muffin treatments $T_{0}$ $\mathrm{T}_{1}, \mathrm{~T}_{2}, \mathrm{~T}_{3}$ and $\mathrm{T}_{4}$ were $37.33,38.45,40.21,41.23$ and
42.11 respectively as shown in Table 4 . The protein quantity, alpha amylase activity and damaged starch might have significant effect on muffin volume and baking quality for composite flours (Butt et al., 1957). It is clear from the studies of Okafor et al. (2012) that values of specific loaf volume decreased by addition of mushroom powder.

\subsection{Textural characteristics of muffin}

The variation of mushroom powder $(0 \%, 10 \%, 20 \%$, $30 \%$, and $40 \%$ ) in muffin had significant effect on the texture of muffin as shown in Table 4 . The mean texture values of muffins treatments $\mathrm{T}_{1}, \mathrm{~T}_{2}, \mathrm{~T}_{3}$ and $\mathrm{T}_{4}$ were $0.55,0.64,0.71,0.67$ and 0.66 , respectively as shown in Table 4.

\subsection{Color}

The color of muffin was determined with the help of color meter as described by Rocha and Morais (2003). The muffins prepared from $40 \%$ supplementation of mushroom powder in wheat flour got minimum color value. The color value of muffin treatments $T_{0} T_{1}$, $\mathrm{T}_{2}, \mathrm{~T}_{3}$ and $\mathrm{T}_{4}$ were $1.03,1.68,1.14,-2.52$ and -1.41 , respectively as shown in Table 4.

\subsection{Scanning analysis of muffins}

The following are images of muffin under scanning electron microscope at different angles which shows pore size description and micro-structural features related to texture of muffin.

Table 3: Mean of proximate analysis.

\begin{tabular}{llllll}
\hline Parameter & $\mathbf{T}_{\mathbf{0}}$ & $\mathbf{T}_{\mathbf{1}}$ & $\mathbf{T}_{\mathbf{2}}$ & $\mathbf{T}_{3}$ & $\mathbf{T}_{\mathbf{4}}$ \\
\hline Moisture & $4.46 \pm 0.37$ & $12.51 \pm 0.50$ & $13.12 \pm 0.26$ & $13.14 \pm 0.66$ & $13.17 \pm 0.46$ \\
Protein & $9.45 \pm 0.28$ & $9.47 \pm 0.37$ & $9.51 \pm 0.19$ & $9.55 \pm 0.47$ & $9.59 \pm 0.28$ \\
Ash & $0.35 \pm 0.01$ & $0.36 \pm 0.01$ & $0.38 \pm 0.01$ & $0.39 \pm 0.02$ & $0.41 \pm 0.02$ \\
Fat & $1.25 \pm 0.04$ & $1.26 \pm 0.05$ & $1.28 \pm 0.02$ & $1.30 \pm 0.06$ & $1.31 \pm 0.03$ \\
Fiber & $0.30 \pm 0.01$ & $0.31 \pm 0.05$ & $0.33 \pm 0.02$ & $0.34 \pm 0.06$ & $0.35 \pm 0.03$ \\
NFE & $76.15 \pm 2$ & $76.09 \pm 1.59$ & $75.38 \pm 0.98$ & $75.28 \pm 3.08$ & $75.17 \pm 2.55$ \\
\hline
\end{tabular}

Table 4: Mean of physical analysis of muffins.

\begin{tabular}{llllll}
\hline Parameter & T0 & T1 & T2 & T3 & T4 \\
\hline Loaf volume $\left(\mathrm{cm}^{3}\right)$ & $155 \pm 7$ & $150 \pm 7.5$ & $147 \pm 7.7$ & $145 \pm 7.60$ & $141 \pm 7.75$ \\
Loaf weight $(\mathrm{g})$ & $37.33 \pm 1.12$ & $38.45 \pm 1.15$ & $40.21 \pm 1.20$ & $41.23 \pm 1.23$ & $42.11 \pm 1.26$ \\
Texture & $0.55 \pm 0.01$ & $0.64 \pm 0.01$ & $0.71 \pm 0.02$ & $0.67 \pm 0.02$ & $0.66 \pm 0.03$ \\
Color A & $1.03 \pm 0.03$ & $-1.68 \pm 0.05$ & $1.14 \pm 0.03$ & $-2.52 \pm 0.07$ & $-1.41 \pm 0.04$ \\
Color B & $19.31 \pm 0.57$ & $17.90 \pm 0.53$ & $13.66 \pm 0.41$ & $14.93 \pm 0.44$ & $14.05 \pm 0.42$ \\
Color Hue & $96.60 \pm 2.89$ & $-6.75 \pm 0.23$ & $94.69 \pm 2.8$ & $-89.35 \pm 2.6$ & $-93.63 \pm 2.8$ \\
Color L & $52.55 \pm 1.57$ & $53.21 \pm 1.59$ & $47.87 \pm 1.43$ & $47.79 \pm 1.43$ & $46.67 \pm 1.40$ \\
Color chroma & $19.33 \pm 0.58$ & $17.97 \pm 0.53$ & $13.70 \pm 0.41$ & $15.14 \pm 0.45$ & $14.12 \pm 0.42$ \\
\hline
\end{tabular}

Journal of Innovative Sciences

June 2021 | Volume 7 | Issue 1 | Page 115 
3.12 Sensory evaluation of muffins

The sensory evaluation of muffin for various attributes such as volume, color, symmetry of formation, evenness of bake, character of crust, grain, and color of crumb, aroma, taste and texture was carried out. The product was evaluated by panel of judges and the results are described below.

\subsection{External characteristics volume}

The results revealed that the scores assigned to volume of muffins were affected significantly by the level of mushroom powder supplementation. The statistical analysis for scores assigned to volume of muffin samples prepared from mushroom powder supplemented in straight grade flour is presented in Table 5. The mean values of treatments of muffin $\mathrm{T}_{0} \mathrm{~T}_{1}, \mathrm{~T}_{2}, \mathrm{~T}_{3}$ and $\mathrm{T}_{4}$ were 9.25, 8.23, 8.10, 7.38 and 7.34 respectively as shown in Table 5 . Replacement of wheat flour with non- wheat flour had certain negative effect on muffin volume. Iqbal (2007) also found that incorporation of mushroom powder in wheat flour significantly reduce the score for volume of muffin. McWalter et al. (2004) also reported that incorporation of mushroom powder in dough had certain negative effect on muffin volume.

\subsection{Color of crust}

Statistical analysis for scores assigned to crust color of muffins prepared from powder supplemented composite flours is presented in Table 5. The mean value of muffin treatments $\mathrm{T}_{0}, \mathrm{~T}_{1}, \mathrm{~T}_{2}, \mathrm{~T}_{3}$ and $\mathrm{T}_{4}$ were $9.19,8.39,7.89,7.12$ and 7.10, respectively as shown in Table 5. The scores assigned to crust color of muffins were significantly affected by the supplementation of mushroom powder. Hussain (2004) found that there was a progressive decrease in assigning the scores to the crust color of muffins as the wheat flour replaced by non-wheat flour. Okafor et al. (2012) reported that scores for color of crust decreased by increasing the level of mushroom powder from control (100\% wheat flour) to $\mathrm{T}_{4}(15 \%$ mushroom powder $)$.

\subsection{Symmetry of form}

The mean values of muffin treatments $\mathrm{T}_{0}, \mathrm{~T}_{1}, \mathrm{~T}_{2}, \mathrm{~T}_{3}$ and $\mathrm{T}_{4}$ were $9.10,8.95,8.17,7.69$ and 7.12 , respectively as shown in Table 5 prepared form $40 \%$ mushroom powder supplemented wheat flour. The scores for symmetry of form were assigned to be the lowest to the muffins prepared form $40 \%$ mushroom powder supplemented wheat flour. Iqbal (2007) also found that incorporation of mushroom powder in wheat flour significantly reduce the score for symmetry of form of muffin.

\subsection{Evenness of bake}

The statistical analysis for evenness of bake score of muffin prepared from the mushroom powder supplemented composite flour are presented in the Table 5. The mean values of muffin evenness of bake treatments $\mathrm{T}_{0}, \mathrm{~T}_{1}, \mathrm{~T}_{2}, \mathrm{~T}_{3}$ and $\mathrm{T}_{4}$ were9.25, 8.98, $8.17,7.84$ and 7.11 respectively as shown in Table 5. (Chavan et al., 1991) observed that the score assigning to evenness of bake decreased as the supplementation level of peanut flour increased.

\subsection{Characteristics of crust}

The statistical results concerning scores allocated to character of crust of muffins prepared from mushroom powder supplemented wheat flour are presented in Table 5.The mean values of muffin treatments $T_{0}, T_{1}$, $\mathrm{T}_{2}, \mathrm{~T}_{3}$ and $\mathrm{T}_{4}$ were 9.60, 8.80, 8.12, 7.95 and 7.13 respectively as shown in Table 5, Oyetaya et al. (2007).

\subsection{Color of crumb}

The statistical results for crumb color of muffin prepared from different levels of mushroom powder in Table 5 . The mean values of crumb color of muffin treatments $\mathrm{T}_{0}, \mathrm{~T}_{1}, \mathrm{~T}_{2}, \mathrm{~T}_{3}$ and $\mathrm{T}_{4}$ were 9.80, 8.45, 8.12, 7.70 and 7.16, respectively as shown in Table 5. The scores assigned by the panelists to crumb color of muffins prepared from different levels of mushroom powder supplementation in wheat flour. Indicate that muffins prepared without mushroom powder supplementation (100\% wheat flour) got significantly the highest scores for crumb color. Is also evident from the results that muffins prepared from 10\% and 20\% mushroom powder supplemented wheat flour had close values.

The results are similar to the finding of Okafor et al., (2012) who observed that scores assigned to the crumb color of muffin decreased as the level of mushroom powder increased.

\subsection{Internal characteristics grain}

The statistical results regarding the scores assigned to grain of muffins prepared from mushroom powder supplemented in wheat flour are presented in Table 6 . The mean values of grain muffins treatments $T_{0}$, $\mathrm{T}_{1}, \mathrm{~T}_{2}, \mathrm{~T}_{3}$ and $\mathrm{T}_{4}$ were $9.12,8.89,8.127 .88$ and 7.22 , respectively as shown in Table 6 . The results indicated that there was a progressive decrease in scores assigned to grain of muffins as the supplementation level of mushroom powder increased. 
Table 5: Means of external characteristics.

\begin{tabular}{llllll}
\hline Parameter & T0 & T1 & T2 & T3 & T4 \\
\hline Volume & $8.25 \pm 0.51$ & $8.23 \pm 0.32$ & $8.10 \pm 0.40$ & $7.38 \pm 0.29$ & $7.34 \pm 0.22$ \\
Color crust & $8.19 \pm 0.51$ & $8.39 \pm 0.33$ & $7.89 \pm 0.15$ & $7.12 \pm 0.35$ & $7.10 \pm 0.21$ \\
Symmetry form & $8.10 \pm 0.27$ & $8.95 \pm 0.35$ & $8.17 \pm 0.16$ & $7.69 \pm 0.38$ & $7.12 \pm 0.28$ \\
Evenness of bake & $8.52 \pm 0.28$ & $8.98 \pm 0.35$ & $8.17 \pm 0.16$ & $7.84 \pm 0.39$ & $7.11 \pm 0.14$ \\
Character of crust & $8.60 \pm 0.28$ & $8.80 \pm 0.35$ & $8.12 \pm 0.16$ & $7.95 \pm 0.39$ & $7.13 \pm 0.14$ \\
Crumb color & $8.80 \pm 0.29$ & $8.45 \pm 0.33$ & $8.12 \pm 0.16$ & $7.70 \pm 0.38$ & $7.16 \pm 0.14$ \\
\hline
\end{tabular}

Table 6: The mean values of taste muffin treatments.

\begin{tabular}{llllll}
\hline Parameters & T0 & T1 & T2 & T3 & T4 \\
\hline Grain & $8.12 \pm 0.27$ & $8.89 \pm 0.35$ & $8.12 \pm 0.16$ & $7.88 \pm 0.39$ & $7.22 \pm 0.21$ \\
Aroma & $8.11 \pm 0.27$ & $8.84 \pm 0.35$ & $8.11 \pm 0.32$ & $7.34 \pm 0.29$ & $7.22 \pm 0.21$ \\
Texture & $8.10 \pm 0.27$ & $8.76 \pm 0.35$ & $8.11 \pm 0.16$ & $7.44 \pm 0.37$ & $7.11 \pm 0.35$ \\
Taste & $8.16 \pm 0.27$ & $8.77 \pm 0.26$ & $8.11 \pm 0.24$ & $7.32 \pm 0.22$ & $7.10 \pm 0.21$ \\
\hline
\end{tabular}

\subsection{Aroma}

The results pertaining to analysis of variance relating to aroma of muffins prepared from different levels of mushroom powder supplementation showed that supplementation levels significantly affected the scores given to aroma of muffins Table 4 . The mean values of aroma muffin treatments $\mathrm{T}_{0}, \mathrm{~T}_{1}, \mathrm{~T}_{2}, \mathrm{~T}_{3}$ and $\mathrm{T}_{4}$ were $9.11,8.84,8.11,7.34$ and 7.22 respectively as shown in Table 6, Okafor et al. (2012).

\subsection{Texture}

The analysis of variance regarding texture of muffins prepared from different composite flours is given in Table 6. The mean values of texture muffins treatments $\mathrm{T}_{0}, \mathrm{~T}_{1}, \mathrm{~T}_{2}, \mathrm{~T}_{3}$ and $\mathrm{T}_{4}$ were 9.10, 8.76, $8.11,7.44$ and 7.11 respectively as shown in Table 6. The results indicated that scores given to texture of muffins differed significantly due to differences in supplementation level of mushroom powder in wheat flour Okafor et al. (2012).

\subsection{Taste}

The statistical results for scores allocated to taste of the muffin samples prepared from different mushroom powder wheat flour blends presented in Table 6 . The mean values of taste muffin treatments $\mathrm{T}_{0}, \mathrm{~T}_{1}$, $\mathrm{T}_{2}, \mathrm{~T}_{3}$ and $\mathrm{T}_{4}$ were 9.16, 8.77, 8.11, 7.32 and 7.10, respectively as shown in Table 6 . The results showed that the muffins prepared from $100 \%$ wheat flour got the highest scores for taste by the panelists. There was a decline in assigning the scores to muffins by increasing the level of mushroom powder supplementation in wheat flour. Okafor et al. (2012) reported that scores allocated to taste of bread decreased as the level of mushroom powder supplementation increased.

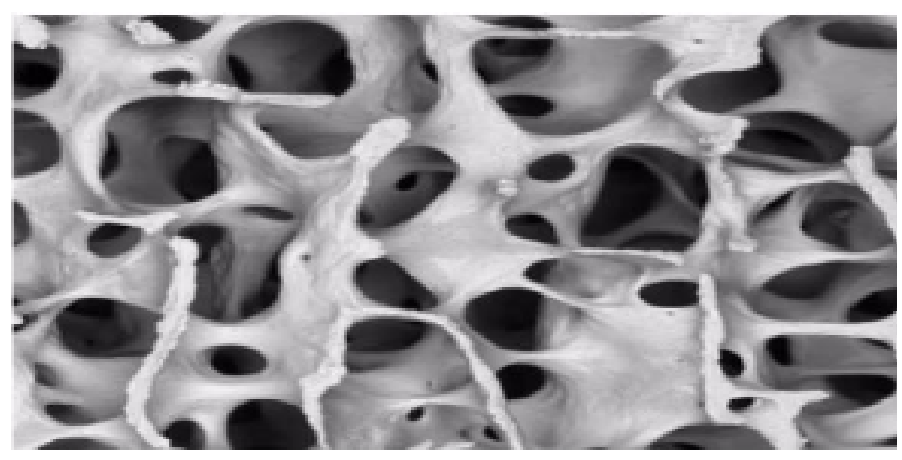

\section{Figure 1: Chemical analysis of muffin.}

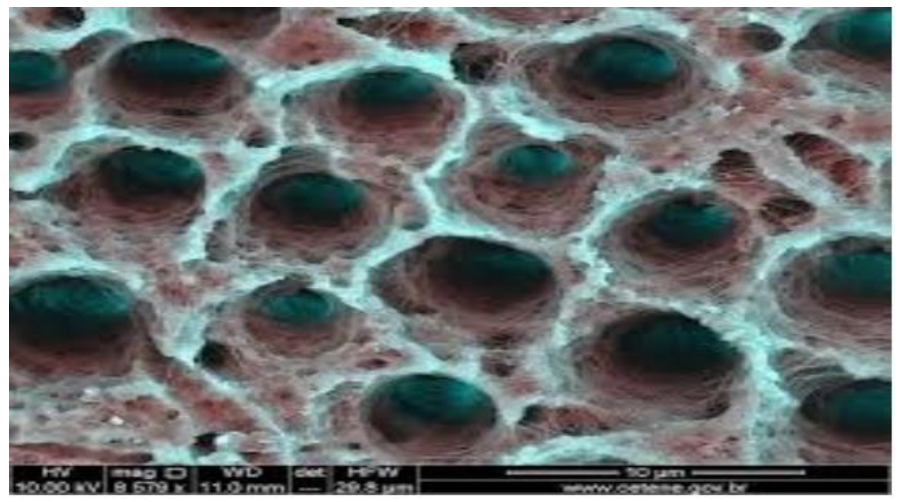

Figure 2: Physical analysis of muffin.

\section{Conclusions and Recommendations}

Wheat flour was supplemented with different levels of mushroom powder for muffin production to improve its protein quality and quantity. Muffin prepared by supplementation of mushroom powder was subjected to physico-chemical analysis and sensory evaluation. Proximate study of mushroom 
enriched muffin showed that mushroom powder not have considerable effect on moisture content of muffin. Ash content, crude protein, crude fiber and crude fat are significantly affect with increased in mushroom powder. Mushroom powder significantly affects color, volume and texture of muffin. Values of color was observed CTn unit that value decrease with increase in mushroom powder. Muffin from control (100\% wheat flour) has maximum color value and its value decreased gradually as the level of mushroom powder supplementation increased in wheat flour. Volume of muffin also decreased with increase in level of mushroom powder. Loaf weight increased with increased in mushroom powder. The sensory characteristics of muffin showed that treatment had significant effect on volume, color of crust, Symmetry of form, evenness of bake, character of crust, grain, and color of crumb, aroma, taste and texture. Significantly lower total scores for muffin were exhibited by the flour supplementation with $10 \%$ and $20 \%$ mushroom powder. Highest scores were obtained by control muffin.

\section{Novelty Statement}

The present study will very helpful to understand characterization of mushroom powder enriched muffins for food scientist.

\section{Author's Contribution}

Muhammad Farooq: Conceptualization, methodology, formal analysis, writing-original draft.

Allah Rakha and Jawad U1 Hassan: Conceptualization, methodology, formal analysis, writing-original draft.

Iftikhar Ahmed Solangi, A. Shakoor, Ibrar Ahmad and Muhammad Bakhtiar: Validation and visualization.

Muhammad Noman Khan, Shoaib Khan and Shabir Ahmed: Help in review.

Wang Yunyang: Conceptualization, writing-review \& editing, supervision.

\section{Conflict of interest}

The authors have declared no conflict of interest.

\section{References}

AACC, 2000. Approved methods of the American association of cereal chemists. $10^{\text {th }}$ ed. AACC

Journal of Innovative Sciences

June 2021 | Volume 7 | Issue 1 | Page 118
Press, MN, USA.2000.

Aguilera, Y., Esteban, R.M., Benitez, V., Molla, E. and Martin, M.A.C., 2009. Starch, functional properties, and microstructural characteristics in chickpea and lentil as affected bt thermal processing. J. Agric. Food Chem., 57(22):1068210688. https://doi.org/10.1021/jf902042r

Aida, F.M.N.A., Shuhaimi, M., Yazid, M. and Maaruf, A.G., 2009. Mushroom as a potential source of prebiotics: A review. Trends in Food Science and Technology. 20: 567-575. https://doi. org/10.1016/j.tifs.2009.07.007

Badifu, S.O., Chima, C.E., Ajaya, Y.I. and Ogori, A.F., 2005. Influence of mango mesocarp flour supplement to micronutrient, physical and organoleptic qualities of wheat based bread. Nigerian Food Journal, 23: 59-68. https://doi. org/10.4314/nifoj.v23i1.33600

Bano, Z., Rajarathnam, S., 1998. Pleurotus mushroom. part 2. chemical composition, nutritional value, post-harvest physiology, preservation, and role as human food. Critical Reviews in Food Science and Nutrition, 27:87-158. https://doi.org/10.1080/10408398809527480

Butt, M.S., Anjum, F.M., Rehman, A. and Ali, A., 1957. Physico-chemical characteristics of spring wheat. Journal of Agricultural Research, 35: 413-422.

Chang, S.T. and Miles, P.G., 1989. Edible mushroom and their cultivation. $1^{\text {st }}$ ed.; Boca Raton, FL, Florida. CRC Press.

Chavan, J.K., Shinde, V.S. and Kadam, S.S., 1991. Utilization of expeller pressed partially defatted peanut cake meal in the preparation of bakery products. Plant Foods for Human Nutrition, 41: 253-259.https://doi.org/10.1007/BF02196394

Corey, M.E., Seetharaman, K. and Beelman, R.B., 2006. The characterization and rheology of wheat flour dough prepared with freeze dried portabella (Agaricus bisporus powder. Institute of Food Technology,

Dikeman, C.L., Bauer, L.L., Flickinger, E.A. and Fahey, G.C., 2005. Effects of stage of maturity and cooking on the chemical composition of select mushroom varieties. Journal of Agriculture and Food Chemistry, 53: 1130-1138. https://doi. org/10.1021/jf0485411

Hesham, A., Eissa, A.S. and Hussein, B.E., 2007. Mostafa rheological properties and quality evaluation of Egyptian balady bread and biscuit supplemented with flours of unterminated and 
germinated legume seed or mushroom. Polish Journal of Food and Nutrition Sciences, 57: 487496.

Hong, G.H., Kim, Y.G. and Song, G.S., 2005. Effect of oyster mushroom (Pleurotus ostreatus) powder on bread quality. Journal of Food Science and Nutrition, 10: 214-281. https:// doi.org/10.3746/jfn.2005.10.3.214

Hussain, S., 2004. Biochemical and technological properties of flaxseed supplemented wheat flour. M.Sc. thesis. National Institute of Food Science and Technology, University of Agriculture, Faisalabad, 2004.

Ibrahium, M. and Hegazy, A., 2014. Effect of replacement of wheat flour with mushroom powder and sweet potato flour on nutritional composition and sensory characteristics of biscuits. Current Science International, 3: 26-33.

Ibrahium, M. and Hegazy, A., 2014. Effect of replacement of wheat flour with mushroom powder and sweet potato flour on nutritional composition and sensory characteristics of biscuits. Curr. Sci. Int., 3: 26-33.

Iqbal, J., 2007. Effect of germinated and fermented cowpea flour on the characteristics of wheat flour and its baked products. M.Sc. thesis. National Institute of Food Science and Technology, University of Agriculture, Faisalabad,

Islam, T., Yu, X. and Xu, B., 2016. Phenolic profiles, antioxidant capacities and metal chelating ability of edible mushrooms commonly consumed in China. LWT - Food Sci. Technol., 72: 423-431. https://doi.org/10.1016/j.lwt.2016.05.005

Kashaninejad, M., Akbari, E., Sobhani, S.M. and Asadi, F., 2016. Potential of sponge cake making using infrared-hot air dried carrot. J. Texture Stud., 47: 34-39. https://doi.org/10.1111/ jtxs. 12165

Kaul, T.N., 2011. Biology and conservation of Mushrooms. New Delhi, India: Oxford and IBH publishing Co. Pvt. Ltd. pp. 117-145.

Keskin, S.O., Sumnu, G. and Sahin, S., 2004. Bread baking in halogen lamp-microwave combination baking. Food Research International, 37: 489-495. https://doi.org/10.1016/j.foodres.2003.10.001

Khan, A.A., Gani, A., Khanday, F.A., Masoodi, F.A., 2017. Biological and pharmaceutical activities of mushroom $\beta$-glucan discussed as a potential functional food ingredient. Bioact. Carbohydrate. Diet. Fibre., 16: 1-13. https://doi. org/10.1016/j.bcdf.2017.12.002
Kim, H.J., Morita, N., Lee, S.H., Moon, K.D., 2001. Scanning electron microscopic observations of dough and bread supplemented with Gastrodiaelata Blume powder. Food Research International, 36: 387-397. https://doi. org/10.1016/S0963-9969(02)00231-4

Land, D.G. and Shephered, R., 1988. Scaling and ranking methods in sensory analysis of foods. $1^{\text {st }} \mathrm{ed}$. Elsevier Applied Science, New York,

Lebesi, D.M. and Tzia, C., 2011. Effect of the addition of different dietary fiber and edible cereal bran sources on the baking and sensory characteristics of cupcakes. Food Bioprocess. Tech., 4: 710-722. https://doi.org/10.1007/ s11947-009-0181-3

Mahamud, M.M., Shirshir, M.R.I. and Hasan, M.R., 2012. Fortification of wheat bread using mushroom powder. Bangladesh Research Publications Journal, 7: 60-68.

Mc-Walter, K.H., Philips, R.D., Walker, S.L., McCullough Semmes-Wilmot, Y., Saalia, F.K. and Hung, Y.C., 2004. Pattersom sparking performance and consumer acceptability of raw and extruded cowpea flour breads. Journal of Food Quality, 27: 3373-3351. https://doi. org/10.1111/j.1745-4557.2004.00660.x

Okafor, J.N.C., Okafor, G.I., Ozumbal, A.U. and Elemo, G.N., 2012. Quality characteristics of bread made from wheat and Nigerian Oyster Mushroom (Pleurotus spp) powder. Pakistan Journal of Nutrition, 11: 5-10. https://doi. org/10.3923/pjn.2012.5.10

Oyetaya, F.L., Akindahunsi, A.A. and Oyetaya, V.O., 2007. Chemical profile and amino acids composition of edible mushrooms pleurotus sajor-caju. Nutrition and Health, 8: 383-389. https://doi.org/10.1177/026010600701800407

Piga, A.P., Catzeddu, S. and Farris, A.T.R., 2005. Sanguinetti ES Texture evaluation of Amaretti cookies during Storage. European Food Research Technology, 221: 387-391. https://doi. org/10.1007/s00217-005-1185-5

Rathore, H., Prasad, S. and Sharma, S., 2017. Mushroom nutraceuticals for improved nutrition and better human health. A review. Pharma Nutrition, 5: 35-46. https://doi. org/10.1016/j.phanu.2017.02.001

Reis, F.S., Martins, A., Vasconcelos, M.H., Morales, P., Ferreira, I.C.F.R., 2017. Functional foods based on extracts or compounds derived from mushrooms. Trends Food Sci. Technol., 66: 48- 
62. https://doi.org/10.1016/j.tifs.2017.05.010

Rocha, A.M.C.N. and Morais, A.M.M.B., 2003. Shelf life of minimally processed apple determined by color changes. Food Control, 14: 13-20. https://doi.org/10.1016/S09567135(02)00046-4

Salehi, F., Kashaninejad, M. and Jafarianlari, A., 2017. Drying kinetics and characteristics of combined infrared-vacuum drying of button mushroom slices. Heat Mass Transfer., 53: 1751-1759. https://doi.org/10.1007/s00231016-1931-1

Salehi, F., Kashaninejad, M., Asadi, F. and Najafi, A., 2016. Improvement of quality attributes of sponge cake using infrared dried button mushroom. J. Food Sci. Technol., 53: 1418-1423. https://doi.org/10.1007/s13197-015-2165-9

Steel, R.G.D., Torrie, J.H. and Dickey, D., 1997. Principles and procedures of statistics: A biometrical approach. $3^{\text {rd }}$ ed. McGraw Hill Book, New York.

Svec, I. and Hruskova, M. 2004. Wheat flour fermination study. Czech J. Food Sci. 22: 17-23.

Wan-Rosli, W.I., Nurhanan, A.R., Aishah, M.S., 2012. Effect of partial replacement of wheat flour with oyster mushroom (Pleurotus sajor caju) powder on nutritional composition and sensory properties of butter biscuit. Sains Malaysiana, 41: 1565-1570.

Yaper, S., Helvaci, S.S. and Peker, S., 1990. Drying behavior of mushroom slices. Drying Technol: Anatomy International Journal, 8: 77-99. https:// doi.org/10.1080/07373939008959865 